\title{
A controlled study of dementia in Parkinson's disease
}

\author{
RHS MINDHAM, SWA AHMED, CG CLOUGH \\ From the University Department of Psychiatry, Leeds, Saxondale Hospital, Nottingham, and the General \\ Infirmary, Leeds
}

SUMMARY Tests of cognitive functions were carried out in a group of patients with Parkinson's disease and repeated after a three-year interval. Comparison was made with a control group drawn from a population of psychiatric patients, matched for age and sex. No differences in cognitive functions were found between the groups, either initially, or between those surviving for three years. Deaths among the index group included a high proportion of patients with cognitive impairment and there was an increasing prevalence and severity of dementia in the index group which exceeded that observed in the control group. Requirements for a methodologically sound study of dementia in Parkinson's disease are discussed.

Since James Parkinson's original description of paralysis agitans many have questioned his statement "the senses and intellect are uninjured" (1817). ${ }^{1}$ Ball was among the first to suggest that intellectual impairment may occur in Parkinson's disease: "paralysis agitans is accompanied more often than is thought by intellectual difficulties" (1882). ${ }^{2}$ Dementia in Parkinson's disease has been estimated to occur in between $14 \%$ and $40 \%$ of those affected by the disorder. ${ }^{3-7}$ Dementia has been described as occurring particularly in the "so-called" arteriosclerotic type of Parkinsonism ${ }^{8}$ but a retrospective study conducted more recently showed evidence of dementia in one third of patients with only minor differences in the proportions of the three main aetiological types: idiopathic Parkinson's disease, postencephalitic Parkinsonism and arteriosclerotic Parkinsonism. ${ }^{9}$

In studies which have used control groups for comparison and standardised methods of assessment of intellectual function the evidence for dementia being a regular feature of Parkinson's disease is less impressive. At least two well-conducted studies have failed to show evidence of dementia in Parkinson's disease. ${ }^{1011}$ Others have agreed with these workers, suggesting that any apparent decline in mental function could be attributed to psychomotor slowing, ${ }^{12}$ or alternatively to the effects of depression of mood. ${ }^{7}$ Against this view, some authors have concluded that there is a "widely generalised

Address for reprint requests: Professor RHS Mindham, University Department of Psychiatry, 15 Hyde Terrace, Leeds LS2 9LT, UK.

Received 27 May 1982 and in revised form 30 July 1982 Accepted 31 August 1982 deterioration" apart from that in motor function or that there is an associated memory impairment in Parkinson's disease. ${ }^{1314}$ In a controlled follow-up study of a large number of subjects $32 \%$ were found to show evidence of dementia and this was ten times the prevalence of dementia among their spouses. ${ }^{15}$ Other evidence is interpreted as suggesting the presence of specific deficits in Parkinson's disease, that these are minor as compared with the motor changes seen, and often static, and that to apply the label of dementia is both "unacceptable and misleading". ${ }^{16}$ Other workers have suggested that the deficit is similar to that seen in patients following frontal lobectomy, although part of their psychological assessment did suggest impairment of shortterm memory and attention. ${ }^{1718}$ An important suggestion is that patients with Parkinson's disease, among others, suffer from a distinct type of dementia attributable to disease of the basal ganglia rather than of the cortex. ${ }^{19}$ This syndrome, known as "subcortical dementia", is characterised by: amnesia, impaired ability to manipulate acquired knowledge, slowness of the thought processes, and changes in personality. Although a clinical picture resembling this description may be seen in Parkinson's disease, the status of "sub-cortical dementia" remains unclear. ${ }^{19} 2021$

The uncertainty which remains over this important issue led us to carry out a further investigation. Our study is based on two hypotheses: firstly, if dementia is a clinical feature of Parkinson's disease rather than a chance finding, it will be more common among patients with the disease than in a control group; and secondly, if dementia is an integral part of the syndrome, progression of the disease will lead to an 
increasing prevalence and severity of dementia among sufferers.

\section{Method}

Forty patients suffering from Parkinson's disease (idiopathic in thirty-seven and postencephalitic in three) were compared with a control group matched for age and sex. The patients suffering from Parkinson's disease were attending a neurological out-patient clinic and the diagnosis was confirmed by two neurologists. The patients continued to receive anti-Parkinson medication.
The control group was selected retrospectively from the outpatient practices of the four consultant psychiatrists who together formed the senior medical staff of the clinical unit of the Department of Psychiatry, Nottingham University Medical School. A control group of this kind was chosen for two reasons: first, we chose to use a "patient" rather than a "normal" control group because there is evidence that any kind of illness may impair performance in tests which measure cognitive function, (D Bannister, personal communication), and we wished to compare two ill groups; and second, it was essential to have control subjects on

Table 1 Male index patients with their matched controls

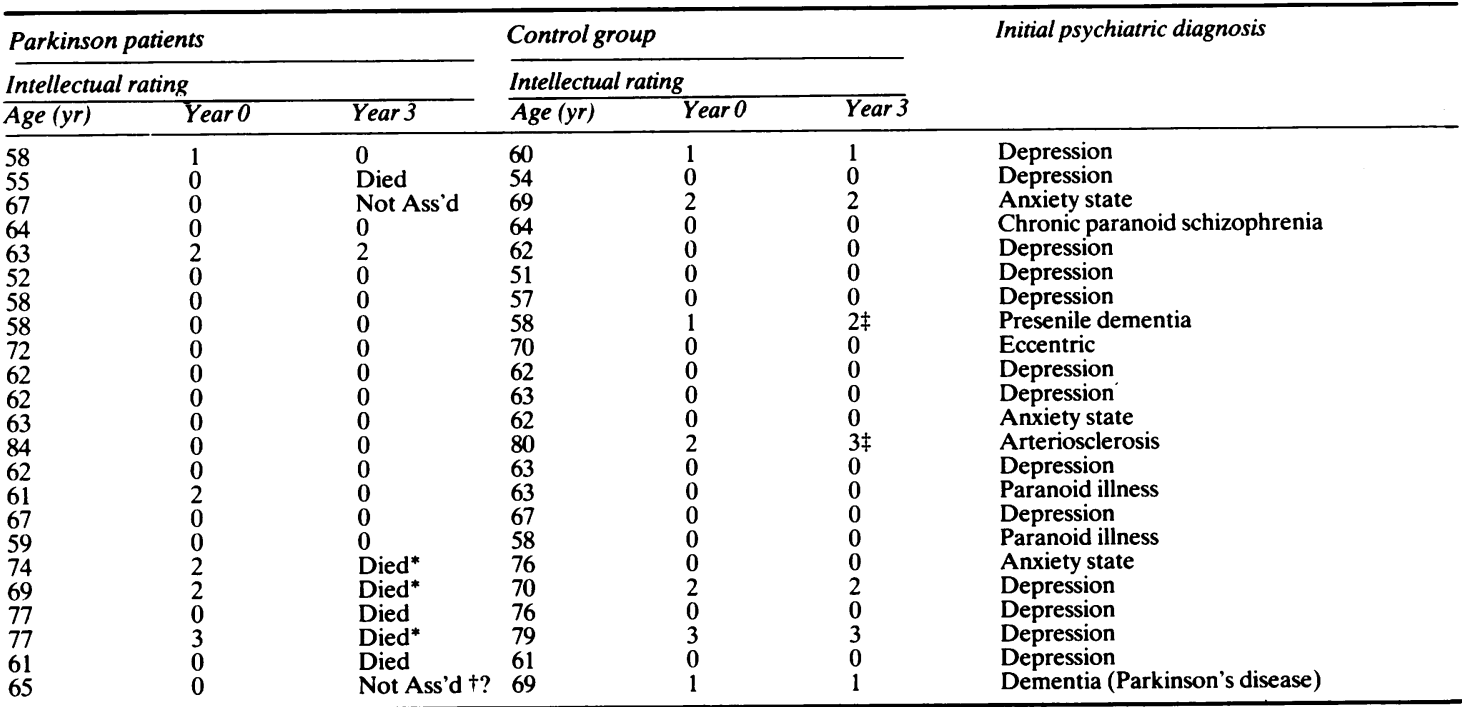

*Patients initially demented who died.

tPatients who became demented during follow-up.

$\ddagger$ Patients who showed progression of dementia.

?Not fully assessed.

Table 2 Female index patients with their matched controls

\begin{tabular}{|c|c|c|c|c|c|c|}
\hline \multicolumn{3}{|c|}{ Parkinson patients } & \multicolumn{3}{|c|}{ Control group } & \multirow[t]{3}{*}{ Initial psychiatric diagnosis } \\
\hline \multicolumn{3}{|c|}{ Intellectual rating } & \multicolumn{3}{|c|}{ Intellectual rating } & \\
\hline Age $(y r)$ & Year 0 & Year 3 & $\overline{\text { Age }(y r)}$ & Year 0 & Year 3 & \\
\hline $\begin{array}{l}62 \\
74 \\
68 \\
61 \\
53 \\
69 \\
70 \\
64 \\
63 \\
70 \\
61 \\
64 \\
64 \\
63 \\
65 \\
68 \\
62\end{array}$ & $\begin{array}{l}1 \\
0 \\
0 \\
1 \\
0 \\
0 \\
0 \\
0 \\
2 \\
0 \\
0 \\
1 \\
1 \\
2 \\
1 \\
1 \\
3\end{array}$ & $\begin{array}{l}\text { Not Ass'd } \\
0 \\
1 \ddagger \\
0 \\
0 \\
0 \\
0 \\
1 \dagger \\
4 \ddagger \\
0 \\
2 \dagger \\
2 \ddagger \\
2 \ddagger \\
2 \\
2 \ddagger \\
3 \ddagger \\
\text { Died* }\end{array}$ & $\begin{array}{l}\text { No contr } \\
76 \\
68 \\
60 \\
53 \\
69 \\
69 \\
64 \\
61 \\
69 \\
60 \\
65 \\
63 \\
64 \\
64 \\
66 \\
61\end{array}$ & $\begin{array}{r}\text { ent } \\
2 \\
0 \\
0 \\
0 \\
2 \\
0 \\
0 \\
0 \\
2 \\
0 \\
0 \\
0 \\
2 \\
0 \\
0 \\
2\end{array}$ & $\begin{array}{l}2 \\
0 \\
0 \\
0 \\
2 \\
0 \\
0 \\
1^{\dagger} \\
2 \\
0 \\
0 \\
0 \\
2 \\
0 \\
0 \\
2\end{array}$ & $\begin{array}{l}\text { Paraphrenia } \\
\text { Anxiety state } \\
\text { Agitated depression } \\
\text { Depression } \\
\text { Senile dementia } \\
\text { Depression } \\
\text { Depression } \\
\text { Anxiety } \\
\text { Depression } \\
\text { Anxiety state } \\
\text { Depression } \\
\text { Depression } \\
\text { Brain damage } \\
\text { Depression } \\
\text { Depression } \\
\text { Presenile dementia }\end{array}$ \\
\hline
\end{tabular}

*Patients initially demented who died.

+Patients who became demented during follow-up.

$\ddagger$ Patients who showed progression of dementia. 
whom full details of cognitive function had been recorded.

The staff of the records department was asked to give the names of patients who had been seen in the out-patient department during a period two to three years previously. Each index patient was individually matched with a control patient by sex and age; this meant that if an index patient was lost to the study, the corresponding control patient was also excluded from comparisons with the survivors of the index group. Because of the relatively narrow age range of the index group, the gathering of the control group was a laborious task. The outcome of the matching procedure is shown in tables 1 and 2 . Once the control group was identified, arrangements were made to reassess the patients on or near the third anniversary of their first out-patient attendance. One of the subjects chosen as a control refused reassessment which left one index patient without a control pairing. The average age of the control group is higher than of the index group: this would increase any psychiatric morbidity closely linked with age in the control group and would be likely to reduce the contrasts between the groups in certain respects.

The index group were assessed using a small battery of tests of cognitive function as part of a more comprehensive study. ${ }^{22}$ They were reassessed using the same battery three years later. The control group were assessed using the same standardised tests at follow-up and their scores three years previously were calculated by scrutiny of the notes recorded by the consultant psychiatrist at the time of their first assessment.

The tests of cognitive function are derived from those used in ordinary clinical practice and include tests of orientation, sentence-learning, counting backwards, counting by threes, digit retention, five-minute memory, a paired word-learning test, simple arithmetic and general knowledge. These tests, which do not include tests of motor skills, were performed in a standardised way and led to each patient receiving a score of intellectual impairment according to the General Practice Research Unit Interview Schedule (1970). ${ }^{23}$

\section{Results}

The index group of forty patients, comprising twentythree men and seventeen women had an average age of 61.9 years. (Average length of illness 9 years, range 1-42 years, 30 on levodopa, six had had neurosurgical treatment.) The average age of the control group was $65 \cdot 7$ years.

Initial Assessment The results of the initial assessment of intellectual function are shown in table 3 . If all the patients showing some evidence of intellectual impairment are grouped together irrespective of severity, $40 \%$ of the index group and $32 \%$ of the control group are seen to be affected. This difference does not reach statistical significance $\left(X^{2}=0.747\right.$, $p=0 \cdot 20, d f=1)$. When only those patients showing intellectual impairment of a degree which is definitely pathological (that is, groups 2,3 and 4) are compared, $20 \%$ of the index group and $24 \%$ of the control group
Table 3 Initial assessment of intellectual function

\begin{tabular}{lccc}
\hline Intellectual rating & \multicolumn{1}{c}{ Index group } & Control group \\
\hline $\begin{array}{l}\text { No abnormality } \\
\text { Mild impairment }\end{array}$ & 0 & $24(60)$ & $27(69)$ \\
Not definitely pathological & 1 & $8(20)$ & $3(8)$ \\
Mild impairment & 2 & $6(15)$ & $8(21)$ \\
Definitely pathological & 3 & $2(5)$ & $1(3)$ \\
Moderate impairment & 4 & $0(0)$ & $0(0)$ \\
Marked impairment & & 40 & 39 \\
Totals & &
\end{tabular}

(Percentages in brackets)

show these levels of impairment; again the difference between the groups is not statistically significant $\left(X^{2}\right.$ $=0 \cdot 18, p=0 \cdot 5, d f=1)$.

Assessment after three years The results of the assessmentc after three-year interval were again compared in the index and control groups. Ten patients were lost from the index group. The survivors were compared with their corresponding controls (table 4). Thirty-three per cent of the index group showed some impairment as compared with $27 \%$ of the control group; this difference is not statistically significant $\left(X^{2}=0 \cdot 314, \mathrm{p}=\mid 0 \cdot 5, \mathrm{df}=1\right)$. When those subjects with "definitely pathological" impairment are compared, there are $26 \%$ in the index group compared with $20 \%$ in the control group; this difference is not statistically significant $\left(X^{\cdot 2}=1 \cdot 14, p=\right.$ $0 \cdot 2, \mathrm{df}=1$ ).

Patients lost at three years Of the ten patients lost to the study seven were known to have died, two were not formally assessed and one was untraced. The two patients not formally assessed were still in contact with the clinic; one was so disabled that she was unable to answer the door and the interviewer was unaware that he should put his hand through the letter box and pull out the key which was on a string; the other patient, who was well-known to the interviewer, came to the door, did not recognise him, and spoke in a way which showed him to be disorientated and disinhibited, saying "We must meet for a drink another time, it's not convenient now". Thus, there is definite knowledge of death in seven subjects of whom four are known to have been

Table 4 Assessment of intellectual function after three years

\begin{tabular}{lcc}
\hline Intellectual rating & Index group & Control group \\
\hline 0 & $20(66)$ & $22(73)$ \\
1 & $2(7)$ & $2(7)$ \\
2 & $6(20)$ & $5(17)$ \\
3 & $1(3)$ & $1(3)$ \\
4 & $1(3)$ & $0(0)$ \\
Totals & 30 & 30 \\
\hline
\end{tabular}

(Percentages in brackets) 
demented, evidence of dementia in one still living and severe disability in another.

Morbidity from dementia In the index group the proportion of subjects initially rated as definitely impaired and surviving to be examined after 3 years was only $13 \%$.

The ten patients lost from the index group were worse than average for the group in terms of intellectual impairment; of the initial assessment $50 \%$ were judged to have some degree of intellectual impairment; $10 \%$ mild, $20 \%$ moderate and $20 \%$ marked. Four of those who died had dementia, and a patient lost to the study but not known to have died was demented at the initial assessment.

Four (including one not fully assessed) index patients showed evidence of dementia for the first time during the follow-up period, as compared with one subject in the control group. Three patients in the index group showed evidence of dementia initially, but this disappeared by the time of the follow-up assessment three years later: this change is likely to be an effect of treatment with levodopa.

Five patients in the index group showed progression in the severity of dementia during the three year period as compared with two patients in the control group.

The details of patients studied and of their controls is shown in tables 1 and 2 and the various indices of morbidity are summarised in table 5 . The numbers of patients involved were so small and the changes observed so diverse as to prevent statistical evaluation of most of the follow-up data.

\section{Discussion}

Although the index and control groups were similar as regards the prevalence of dementia initially, by the end of the three year follow-up period, evidence had accumulated which demonstrates a higher morbidity from dementia among the patients with Parkinson's disease. This was shown in three ways: patients suffering from dementia were more likely to die during the period of study, only $13 \%$ surviving 3 years; dementia observed for the first time during the

\section{Table 5 Overall morbidity from dementia compared}

\begin{tabular}{llc}
\hline Indices of morbidity & $\begin{array}{l}\text { Parkinson's } \\
\text { disease patients }\end{array}$ & Control patients \\
\hline $\begin{array}{l}\text { Patients found to be demented } \\
\text { at initial assessment }\end{array}$ & 16 & 12 \\
$\begin{array}{l}\text { Patients demented after } 3 \mathrm{yr} \\
\text { Deaths among patients }\end{array}$ & 10 & 8 \\
$\begin{array}{c}\text { demented at initial assessment } \\
\text { Patients found to be demented } \\
\text { only after } 3 \mathrm{yr}\end{array}$ & 4 & - \\
$\begin{array}{l}\text { Patients showing worsening of } \\
\text { dementia over } 3 \mathrm{yr}\end{array}$ & $3(+1)$ & 1 \\
\hline
\end{tabular}

follow-up period was more common in the index group; there was more evidence of progession in the severity of dementia in the index group. On these findings we are unable to reject either of our initial hypotheses. Within the methodological limits of this small scale study it seems likely that dementia occurs more commonly in Parkinson's disease than in a psychiatric population, and should be regarded as an intrinsic part of the disorder as it occurs with increasing prevalence and severity as the disease progresses. These conclusions must be qualified and do not constitute final evidence of the status of dementia in Parkinson's disease: a larger scale study with certain improvements in method is required for the matter to be finally clarified.

The incidence of dementia in our index group initially was $20 \%$; this is a low figure by comparison with some other studies. Celesia and Wanamaker believed that $40 \%$ of their patients with Parkinson's disease showed some evidence of dementia. ${ }^{4}$ Martilla and his colleagues found an overall incidence of dementia of $28.8 \% .^{5}$ Pollack and Hornabrook, ${ }^{24}$ found significant mental deterioration in $20 \%$ and Hoehn and Yahr found an incidence of "mild to moderate organic mental syndrome" in $14 \% .^{3}$ These studies did not, however, involve comparison with control populations. Loranger and his colleagues, using the Wechsler Adult Intelligence Scale on a patient group alone, found impairment in $36.5 \%$ and conclude that the intellectual decline is twice that of the normal population of the same age. ${ }^{25}$ Lieberman and his colleagues found $32 \%$ of 520 patients to have impaired cognitive functioning and that this was ten times the prevalence of dementia among 407 spouses. ${ }^{15}$ These workers and others have suggested that there is a sub-group of patients with Parkinson's disease in which dementia is a prominent feature. ${ }^{26}$ Our results are compatible with this suggestion without providing positive evidence in support. There is some pathological data which suggests a relationship between the dementia of Parkinson's disease and that of Alzheimer's disease. ${ }^{27} 28$

The low incidence of dementia in our patients as compared with other studies and the loss of demented patients due largely to death, questions the adequacy of the method of our study in bringing out any difference which might exist between the index and control groups. Two aspects of the method of the study require special scrutiny: first, was the 'ype of control group appropriately chosen; and secondly, were adequate methods used in assessing intellectual function?

The control group was taken from a large population of patients who had seen a psychiatrist at least once. This group of patients might be expected to contain some patients suffering from dementia and 
probably a higher proportion than would be found in the general population. In this way the composition of the control group would reduce any contrast between the index group and the control group with respect to dementia. On the other hand, the presence of an illness of any kind is known to impair performance on tests of intellectual function in a nonspecific way so that the choice of a "patient" control group was more appropriate than a group of normal subjects. Our experience suggests that a control group drawn from non-psychiatric patients would have been more satisfactory, probably leading to a reduction in the proportion of patients suffering from dementia and thereby sharpening any contrast with the index group. A "spouse" control group has been used in some studies and has proved to be fairly satisfactory. ${ }^{15}$ There are, however, several problems with this approach: not all patients have spouses; spouses tend to be younger than patients; spouses are generally a "well" group and would be expected to show less cognitive impairment than a "patient" group. (D Bannister, personal communication).

Our control group was less satisfactory than it might have been because it was selected retrospectively; this meant that the initial assessment was carried out by a clinician for purely clinical purposes without using the standardised assessment subsequently used in follow-up. This method of choosing the control group prevented comparison of death rates in the groups as selection meant that the control subjects had already survived the follow-up period. A control group studied prospectively and in parallel with the index group would be more satisfactory but would require a large scale study.

There are particular problems in assessing cognitive function in patients suffering from Parkinson's disease and these have to be considered in making a choice of methods of assessment. ${ }^{29}$ Patients are usually slow both in action and in thought and often have difficulty in sustaining concentration. Furthermore, it is important to use tasks which all subjects in a study are capable of completing on each occasion on which they are administered. A compromise has to be made between rigour and practicability. For these reasons we chose a relatively short and simple battery of tests which included none which depend upon motor skills. This battery is not refined and has not been subjected to rigorous tests of reliability; it was, however, administered in a standardised way and was found to be acceptable to patients and understood by them. In spite of the choice of a relatively simple battery of tests some patients required 45 minutes to complete it; this must be close to the limit of concentrated application in such a group of patients. The methods of assessment used in the well controlled and informative study by Lieberman and his colleagues, were of a similar kind and have the same strengths and weaknesses. ${ }^{15}$

A matter which requires comment is the possible effect of treatment with levodopa on performance in tests of cognitive functions. A number of studies have reported improvement in intelligence, perceptual, motor and memory functions, following administration of levodopa. These effects are more limited when treatment and observations are continued over a period of years. ${ }^{29}$ Various explanations of the effect of levodopa on cognitive functions have been put forward; but the most favoured is that the effect is mediated through enhanced arousal or activation in a non-specific way. ${ }^{30}$

Our study, which is methodologically different from studies previously performed, brings further evidence which suggests that dementia is a regular feature of Parkinson's disease. This evidence, and the evidence from previous studies, is not, however, conclusive. Our study highlights some of the methodological problems in investigating dementia in Parkinson's disease, and it would appear that a completely satisfactory study has not yet been completed. Our experience underlines the importance of an appropriately selected control group, the use of standardised and appropriate methods of assessment which can be successfully carried out in patients with Parkinson's disease, the study of patients over a suitable period of time with measures which allow for the loss of patients from relevant causes, and numbers of subjects and controls which would allow full statistical evaluation of the results. The possible existence of a sub-group of patients with Parkinson's disease in which dementia is a regular feature, and the status of the concept of "sub-cortical dementia" deserve further investigation.

We are indebted to the following medical colleagues: Professor CD Marsden, Dr JD Parkes and Dr KJ Zilkha of King's College Hospital for allowing us to study patients suffering from Parkinson's disease who were attending their out-patient clinics, Professor JE Cooper, Dr IB Pearson and Dr DA Toms of Mapperley Hospital, Nottingham, for allowing us to select the control group from their patients.

The research was supported financially by the Trent Regional Health Authority. We are grateful to Mrs Ann Hawkins and Miss Teresa James for their help in preparing the manuscript.

\section{References}

' Parkinson J. An essay on the shaking palsy. London: Sherwood, Neely and Jones, 1817.

2 Ball B. De l'insanité dans la paralysie agitante. Encéphale 1882;2:22-32.

${ }^{3}$ Hoehn MM, Yahr MD. Parkinsonism: onset, pro- 
gression and mortality. Neurology (Minneap) 1967; 17:427-42.

+ Celesia GG, Wanamaker WM. Psychiatric disturbances in Parkinson's disease. Dis Nerv System 1972;33: 577-83.

5 Martilla RJ, Rinne VK. Dementia in Parkinson's Disease. Acta Neurol Scand 1976;54:431-41.

- Shaw KM. Lees AJ, Stern GM. The impact of treatment with levodopa on Parkinson's disease. $Q J$ Med 1980 ; 49:283-93.

7 Mayeux R, Stern Y, Rosen J, Leventhal J. Depression, intellectual impairment, and Parkinson's disease. Neurology (NY) 1981;31:645-50.

* Critchley M. Arteriosclerotic Parkinsonism. Brain 1929;52:23-83.

9 Mindham RHS. Psychiatric symptoms in Parkinsonism. J Neurol Neurosurg Psychiatry 1970;33:188-91.

10 Mettler FA, Crandell A. Relationship between Parkinsonism and psychiatric disorder. J Nerv Ment Dis 1959;129:551-63.

1 Talland GA. Cognitive function in Parkinson's clisease. J Nerv Ment Dis 1962;135:196-205.

12 Asso D. W.A.I.S. scores in a group of Parkinson patients. Br J Psychiatry 1969;115:555-6.

13 Reitan, RM, Boll TJ. Intellectual and cognitive functions in Parkinson's disease. J Cons Clin Psycho! 1971; 37:364-9.

14 Warburton JW. Memory disturbance and the Parkinson syndrome. Br J Med Psychol 1967;40:169-71.

15 Lieberman A, Dziatolowski M, Kupersmith M, Serby M, Goodgold A, Korein J, Goldstein M. Dementia in Parkinson's disease. Ann Neurol 1979;6:355-9.

${ }^{16}$ Mathews CG, Haaland YK. The effect of symptom duration on cognitive and motor performance in Parkinsonism. Neurology (Minneap) 1979;19:951-6.

17 Bowen FR, Kamienny RS, Burns MM, Yahr MD. Parkinsonism: effects of levodopa treatment on concept formation. Neurology (Minneap) 1975;25: 701-4.

18 Bowen DM, Davidson AN. Extrapyramidal disease and dementia. Lancet 1975;i:1199-1200.

19 Albert ML, Feldman RG, Willis AL. The sub-cortical dementia of progressive supra nuclear palsy. $J$ Neurol Neurosurg Psychiatry 1974;38:121-30.

20 Mortimer JA, Pirozzolo FJ, Hansch EC, Webster DD. Relationship of motor symptoms to intellectual deficits in Parkinson's disease. Neurology (NY) 1982;32: 133-7.

${ }^{21}$ Mayeux R, Stern Y, Rosen J, Benson DF. Subcortical dementia: a recognisable clinical entity. Ann Neurol 1981;10:100-1.

22 Mindham RHS, Marsden CD, Parkes JD. Psychiatric symptoms during 1-dopa therapy for Parkinson's disease and their relationship to physical disability. Psychol Med 1976;6:23-33.

${ }^{23}$ General Practice Research Unit. The General Practice Research Unit Interview Schedule. London: Institute of Psychiatry, 1970.

${ }^{24}$ Pollack M, Hornabrook RW. The prevalence, natural history and dementia of Parkinson's disease. Brain 1966;89:429-48.

${ }^{25}$ Loranger AW, Goddell H, McDoweil FH, Lee JE, Sweet RD. Intellectual impairment in Parkinson's syndrome. Brain 1972;95:405-12.

26 Garron DC, Klawans HL, Narin F. Intellectual functioning of persons with idiopathic Parkinsonism. $J$ Nerv Ment Dis 1972;154:445-52.

27 Hakim AM, Mathieson G. Dementia in Parkinson's disease: a neuropathologic study. Neurology (Minneap) 1979;29:1209-14.

${ }^{28}$ Sugimura K, Yamasaki Y. Parkinson's disease accompanied by dementia. Riusho Shinkelgoku 1977; 17(8):5:513-9.

29 Stratigopoulos EA. Neuropsychological investigation of Parkinson's disease: a comparative study using test procedures investigating cognitive functions on patients before administration of 1-dopa and after short-term and long-term l-dopa therapy. Unpublished M.Sc. dissertation, University of Leeds, 1980.

${ }^{30}$ Riklan M, Whelitan W, Cullinan T. Levodopa and psychometric test performance in Parkinsonism five years later. Neurology (Minneap) 1976;26:173-9. 